\title{
Sexting na adolescência: problematizando seus efeitos no espaço escolar
}

\author{
Suzana da Conceição de Barros* \\ Paula Regina Costa Ribeiro** \\ Raquel Pereira Quadrado***
}

\section{Resumo}

Este artigo tem como propósito analisar o fenômeno do sexting em alguns materiais, como reportagens, matérias, programas televisivos e comentários, postados na internet, a fim de discutir como essa prática está entrelaçada com a escola. $\mathrm{O}$ termo sexting é o resultado da união de duas palavras sex (sexo) texting (envio de mensagens). Esse conceito descreve uma prática sociocultural que consiste no compartilhamento de mensagens escritas, de fotos e de vídeos, de caráter erótico/sensual/sexual, por meio de algumas tecnologias digitais. Desse modo, este trabalho é de caráter qualitativo e está vinculado as pesquisas sociais. Para a produçáo dos dados, utilizamos a internet como instrumento de pesquisa. Em relação à análise dos dados coletados, utilizou-se algumas ferramentas da análise do discurso foucaultiana. Ao realizar a análise dos dados, verificou-se que a escola está atrelada à questôes relacionadas ao sexting, pois quando esta não serve como cenário para a produção dos vídeos e fotos torna-se um espaço de discussão, comentários e de repercussão dessa prática. Além disso, a mídia massiva, ao mencionar o nome, colocar o endereço e publicar fotos das escolas envolvidas com os casos do sexting, acaba expondo e "punindo" essa instituição. Também evidenciamos que a escola é entendida como um espaço importante para as discussóes relacionadas às sexualidades. Nesse sentido, entende-se que o sexting vem produzindo efeitos na escola, o que aponta para a necessidade de essa instância discutir temas relacionados aos corpos, às sexualidades, aos gêneros e às tecnologias, para além do enfoque biologicista.

Palavras-chave: Sexting. Escola. Tecnologias digitais.

\footnotetext{
* Doutora em Educação em Ciências pela Universidade Federal do Rio Grande (FURG). Professora de Ciências no Município do Rio Grande, RS.

** Doutora em Ciências Biológicas pela Universidade Federal do Rio Grande do Sul (UFRGS). Professora do Instituto de Educação na dos Programas de Pós-Graduação em Educaçáo Ambiental, Educação em Ciências (Associação Ampla FURG/UFRGS/UFSM) e Pós-Graduação em Educação da Universidade Federal do Rio Grande (FURG).

*** Doutora em Educaçấo em Ciências pela Universidade Federal do Rio Grande (FURG). Professora do Instituto de Educação e dos Programas de Pós-Graduação em Educação em Ciências (Associação Ampla FURG/UFRGS/UFSM) e da Pós-Graduação em Educação da Universidade Federal do Rio Grande (FURG).
} 


\section{Contextualizando o estudo}

Neste artigo, buscamos analisar o fenômeno sexting em alguns materiais, como reportagens, matérias, programas televisivos e comentários, postados na Internet, a fim de discutir como essa prática está entrelaçada com a escola.

O termo sexting foi criado no século XXI, nos Estado Unidos da América. É o resultado da uniáo de duas palavras: sex (sexo) e texting (envio de mensagens). Esse conceito faz menção a uma prática sociocultural, que consiste no compartilhamento de mensagens escritas, de fotos e de vídeos, de caráter erótico/sensual/sexual, por meio de algumas tecnologias digitais (smartphones, celulares, e-mails, sites de redes sociais, webcams, entre outras), com pessoas próximas e conhecidos/as (como namorados/as, "ficantes", "paqueras", amigos/as) ou para desconhecidos/as, quando postado na internet, por exemplo (SAFERNET, [2012]). Nesse sentido, o sexting consiste na exposição da sexualidade para um indivíduo específico ou para uma multidão; este pode ser entendido como uma manifestaçáo da espetacularização do eu (SIBILIA, 2008).

A prática do sexting vem sendo realizada por sujeitos de diversas faixas etárias (crianças, adolescentes e adultos/as). Em nossos estudos, analisamos materiais que abordam a prática do sexting com crianças e adolescentes. Alguns estudos realizados nos Estados Unidos da América, Europa e no Brasil mostram que existe um número significativo de sujeitos que já entraram em contanto com essa prática. Alguns produzem e compartilham materiais de cunho sexual, enquanto outros têm acesso a estes.

No Brasil, uma pesquisa realizada pela Safernet Brasil ([2012]) apontou que cerca de $12 \%$ dos/as adolescentes participantes do estudo já praticaram sexting. Nos Estados Unidos da América, uma pesquisa parecida encontrou números maiores de praticantes de sexting: cerca de $20 \%$ dos/as adolescentes afirmaram ter compartilhado fotos e vídeos relacionados à sexualidade e à intimidade. Na Europa, a Edukids ${ }^{1}$ descobriu que $15 \%$ desses sujeitos já se envolveram de alguma forma com a prática do sexting (compartilhando ou recebendo). Assim, podemos entender o sexting como uma prática que vem se expandido pelo mundo todo. Também evidenciamos isso nos cursos de formação continuada que realizamos com professores/as da Educação Básica, em que sempre são relatados casos dessa prática.

Entendemos que a emergência desse fenômeno está relacionada com diversos fatores, tais como: popularização e democratização das tecnologias digitais, a conquista e sedução de parceiros/as, a vivência de novas sensaçôes e prazeres, a necessidade de adquirir visibilidade, o afrouxamento de fronteiras entre o âmbito público e o privado, a constituição da sociedade do espetáculo, entre outros. Nesse viés, a sexualidade torna-se 
uma mercadoria, isto é, algo a ser negociado em troca de "fama", visibilidade ou de uma determinada conquista. Esse fenômeno permite-nos evidenciar a constituiçáo de outros modos de viver a sexualidade.

Entendemos a sexualidade como uma construção social, cultural, biológica e histórica, que está articulada a poderes e saberes e que é produzida por meio de diversos discursos que circulam em nossa sociedade (FOUCAULT, 2007a). Sem assim, esta pode ser entendida como um dispositivo histórico ${ }^{2}$, pois se constituiu ao longo da modernidade como um domínio que precisava ser conhecido, analisado e investigado, por diversas instâncias, instituiçóes e campos do saber. Isso possibilitou que ocorresse uma proliferaçáo discursiva. Ou seja, diversos saberes foram produzidos sobre esse tema. Além disso, está conectada com relações de poder, pois esses saberes são produzidos por meio de uma multiplicidade de forças, lutas e estratégias, que estão presentes nas diversas relaçóes entre os sujeitos. Um exemplo disso é que náo são todos os sujeitos considerados com autoridade para discutir sobre esse assunto.

O dispositivo da sexualidade atua no gerenciamento e administração da sexualidade e está vinculado à constituição de sujeitos, que são produzidos pelas normalizações estabelecidas. Esse dispositivo tem como "razão de ser, não o reproduzir, mas o proliferar, inovar, anexar, inventar, penetrar nos corpos de maneira cada vez mais detalhada e controlar as populaçôes de modo cada vez mais global" (FOUCAULT, 2007a, p. 118).

Para controlar a população, diversas instituiçóes sociais e campos do saber, tais como a família, a escola, o exército, a Medicina, a Psicologia etc., foram convocados a observar, disciplinar e esquadrinhar a vida dos sujeitos, a fim de produzir saberes sobre a sua sexualidade e regulá-la. Dentre essas instituiçôes, a escola tem se destacado, pois a educaçáo escolarizada é considerada pelo Estado, por meio do Estatuto da Criança e do Adolescente (ECA) (BRASIL, 2005), uma passagem obrigatória para as crianças e os/as adolescentes. Esses sujeitos têm o direito de ter acesso a esta. Desse modo, a maioria dos sujeitos transita nessa instituição, por um período considerável de suas vidas. A democratização e a obrigatoriedade da educação escolarizada vêm com o propósito de promover um disciplinamento nos sujeitos, inculcando comportamentos, normas e padróes. A escola pode ser considerada uma eficiente maquinaria de normalizaçáo e produção de sujeitos disciplinados. Para Alfredo Veiga-Neto (2003, p. 107), "a instituição escolar pode ser entendida como uma maquinaria capaz de moldar subjetividades para algumas formas muito particulares de viver socialmente o espaço e o tempo". Assim, a escola não ensina apenas conteúdos "ditos científicos"; transmite modos de ser e regula as vida dos sujeitos. 
Nessa perspectiva, as instituiçóes pedagógicas também se tornaram instâncias que se ocuparam em controlar, vigiar e normalizar a sexualidade das crianças e dos/as adolescentes. Diferentemente do que muitas vezes se afirma sobre o fato de as escolas não falarem sobre sexualidade, Foucault (2007a, p. 36) salienta que, "desde o século XVIII, ela [instituição pedagógica] concentrou as formas de discurso nesse tema; estabeleceu pontos de implantaçáo diferentes; codificou os conteúdos e qualificou os locutores".

Desse modo, as escolas, ao invés de imporem um silêncio em torno do sexo, vêm atuando na incitação dos discursos relacionados à sexualidade, com base em algumas regras que regulam tais discursos. Para tanto, estabelecem algumas estratégias de podersaber que ensinam modos der ser, estar, pensar e se comportar em relação à sexualidade. Segundo Louro (2007, p. 31), na "escola, pela afirmação ou pelo silenciamento, nos espaços reconhecidos e públicos ou nos cantos escondidos e privado, é exercida uma pedagogia da sexualidade, legitimando determinadas identidades e práticas sexuais, reprimindo e marginalizando outras".

Por meio de diversas práticas pedagógicas; ou seja, das regras estabelecidas (roupas permitidas e proibidas), dos artefatos culturais utilizados (livros, vídeos, charges etc.), da organizaçáo dos espaços (filas, banheiro, sala de aula), da postura de professores/as e de todos/as os/as envolvidos/as, as escolas constituem os sujeitos de um determinado modo.

Essa pedagogia da sexualidade, que disciplina os corpos e as sexualidades dos sujeitos, é realizada de forma minuciosa e discreta, passando muitas vezes despercebidas no cotidiano escolar. Assim, "tal pedagogia é muitas vezes sutil, discreta, contínua, mas, quase sempre, eficiente e duradoura” (LOURO, 2007, p. 17).

Além de realizar uma pedagogia normalizadora da sexualidade, a escola também atua no controle dos sujeitos. Para tanto, ela cria diversas estratégias (estabelece posiçóes na sala de aula, regula o uso do banheiro, coloca câmeras em alguns locais, contrata inspetores/as, entre outros) para regular e conhecer com minúcias as atitudes dos sujeitos. "Os construtores e organizadores escolares haviam se colocado 'num estado de alerta perpétuo' em relação à sexualidade daqueles que circulam na instituiçâao escolar" (LOURO, 2008, p. 106).

Todo esse disciplinamento e controle dos sujeitos são realizados com o intuito de que a sexualidade não fosse exposta e escancarada na escola; ou seja, que esta se restringisse ao âmbito privado. Assim, a escola ensina que a sexualidade é uma questão privada, que não deve estar nesse espaço, que é considerado um espaço público. "Através de múltiplas estratégias de disciplinamento, aprendemos a vergonha e a culpa; experimentamos a censura e o controle. Acreditando que as questóes da sexualidade são 
assuntos privados, deixamos de perceber sua dimensão social e política" (LOURO, 2007, p. 27).

O sexting coloca esse entendimento em xeque, pois mostra que essas temáticas também estão presentes nesse espaço. Além disso, esse fenômeno desestabiliza-nos por expor algo que é entendido como do âmbito privado, como a sexualidade, por exemplo. Nesse viés, este artigo enfoca a discussão do sexting e a sua relação com a instituição escolar.

\section{Tecendo os caminhos metodológicos}

Este artigo é de caráter qualitativo, e está vinculado a pesquisas sociais, que têm como propósito conhecer e entender fenômenos sociais e culturais presentes em nossa sociedade. Este estudo pode ser considerado uma pesquisa social, pois procura entender um fenômeno sociocultural, o sexting, em sua complexidade.

Sabemos que um dos problemas enfrentados pelas pesquisas sociais são as ferramentas utilizadas para produçáo dos dados, pois, para aprofundar os estudos, é importante ter uma estratégia que facilite o acesso de materiais em larga escala. No entanto, poucos são os métodos que possibilitam entender um determinado fenômeno amplamente. A internet pode ser considerada uma grande oportunidade para as pesquisas sociais, pois possibilita que consigamos produzir dados em nível macro; ou seja, temos mais acessos aos materiais que desejamos, como salientam Halavais (2012) e Fragoso, Recuero e Amaral (2012). Nesse estudo, utilizamos a internet para a produção dos dados, porque entendemos que esta possibilitou-nos ampliar nosso corpus de análise.

Utilizamos a internet como "instrumento" de pesquisa; ou seja, como um ambiente de produção dos dados empíricos (FRAGOSO; RECUERO; AMARAL, 2012). A busca dos dados foi realizada por meio do site da empresa online Google.

A fim de encontrar materiais que discutissem de alguma forma sobre o sexting, utilizamos alguns termos chaves, tais como: "sexting", "vídeos de adolescentes postados na internet", "fotos sensuais de adolescentes na internet", "reportagens sobre vídeos de sexo entre adolescentes na internet".

No total, encontramos 48 materiais na internet, que relatavam casos sobre sexting e discutiam essa prática. Dentre esses materiais, tivemos acesso às notícias e reportagens publicadas em revistas e jornais, presentes em sites e portais de informação, postagens de blogs e alguns programas televisivos postados no Youtube. Alguns desses materiais continham comentários de internautas sobre as situaçôes relatadas. Tais comentários também passaram a fazer parte do corpus de análise. 
Ao olhar os materiais, evidenciamos que, dentre os dados produzidos, trinta e sete (37) destes discutiam sobre casos relacionados à produção de vídeos caseiros que mostravam relaçóes sexuais. É importante destacar que alguns desses materiais discutiam sobre os mesmos casos, mas com enfoques diferentes: três (3) abordavam discussóes sobre a prática de publicaçấo de fotos sensuais; e oito (8) falavam de modo geral sobre o sexting: causas, consequências, modas, competiçôes, relação dos pais e da escola, sexualidade adolescente etc.. Foram selecionados os materiais postados no período de 2008 a 2012. Neste artigo, analisamos dezesseis (16) materiais, que trazem enunciaçôes relacionadas ao espaço da escola.

Para a análise dos dados coletados, utilizamos algumas ferramentas da Análise do Discurso foucaultiana. Investigamos as enunciações presentes no material empírico produzido que abordassem a relação entre o sexting e a escola.

As enunciações podem ser narrativas, imagens, vídeos etc., ou seja, estas são um conjunto de signos que emergem em um determinado momento social, cultural, econômico, histórico e político. Assim, as enunciaçôes podem ser compreendidas como acontecimentos que são contingentes e singulares. Quando a multiplicidade de enunciaçóes "fala" sobre o mesmo objeto, forma-se o enunciado. Para Foucault (2009, p. 36), "os enunciados, diferentes em sua forma, dispersos no tempo, formam um conjunto quando se referem a um único e mesmo objeto". Esses conjuntos de enunciados estão apoiados em formaçôes discursivas. São os conjuntos de enunciados, ancorados em uma determinada formaçáo discursiva que formam um determinado objeto, ou seja, que estáo constituindo um determinado discurso. Entendemos, assim, que a mídia vem produzindo um discurso sobre a prática do sexting.

Seguindo algumas ferramentas da Análise do Discurso, ao analisarmos os elementos que formam o discurso, como as enunciaçóes, por exemplo, buscamos fugir de interpretaçóes. De acordo com Foucault (2007b), ao realizar a análise discursiva, temos que nos preocupar com a regra da exterioridade. Isto é, não devemos olhar os discursos procurando em que lugar está:

[...] o seu núcleo interior e escondido, para o âmago de um pensamento ou de uma significação que se manifestariam nele; mas, a partir do próprio discurso de sua aparição e de sua regularidade, passar às suas condiçóes externas de possibilidade, àquilo que dá lugar à série aleatória desses acontecimentos e fixa suas fronteiras. (FOUCAULT, 2007b, p. 53).

Dessa forma, neste trabalho procuramos analisar o material empírico sem procurar encontrar o que está presente em suas entrelinhas. Em vez disso, enfocamos no 
que está dito. Além disso, buscamos entender as condiçóes de existência dos dados, ou seja, discutimos o que possibilitou que os materiais postados na internet apontassem para a escola como uma instituição implicada nas questôes relacionadas ao sexting. Para Rosa Fischer (2001, p. 198-199), realizar a análise do discurso é dar conta de conhecer "[...] as relaçôes históricas, de práticas muito concretas, que estão 'vivas' nos discursos". Por esse viés, escolher essa estratégia de análise é procurar conhecer os processos históricos e socioculturais que estão envolvidos na constituiçấo dos discursos sobre sexting.

É esse o caminho que seguimos: olhar o discurso em sua exterioridade e conhecer suas condiçóes de existências, para analisar o que vem sendo dito pela mídia sobre o entrelaçamento da prática do sexting com as escolas.

\section{Discutindo os entrelaçamentos entre o sexting e a escola}

Ao analisarmos os materiais empíricos que discutem sobre sexting, podemos evidenciar que alguns vídeos foram gravados no interior da escola. Assim, alguns espaços dessas instituiçóes, como as salas de aula, os banheiros e as quadras esportivas, serviram de cenário para a produção de vídeos eróticos/sexuais. Conforme podemos perceber nos seguintes fragmentos:

Um vídeo de dois alunos adolescentes fazendo sexo numa sala de aula de uma escola pública chocou a cidade de São Carlos, interior de São Paulo. Segundo um jornal local, as imagens foram gravadas a pedido da adolescente de 14 anos. O rapaz tem 15. (ALUNA..., 2011, grifo nosso).

No Paraná, no principal colégio do Estado, as cenas de sexo, entre uma aluna e dois estudantes, foram no banheiro. (VÍDEO..., 2009a, grifo nosso).

Além disso, quando a escola não serve de cenário para a produção de vídeos e fotos, de cunho sexual/erótico/sensual, esta se torna um espaço de repercussão dessas práticas que acontecem fora desse local. Tais situaçôes se tornam polêmicas, passando a ser alvo de comentários e julgamentos na comunidade escolar, conforme podemos notar nos excertos a seguir:

Uma das meninas envolvidas estudava no maior colégio da cidade. Os professores tiveram que interromper as aulas para tratar do tema. (WOBETO, 2011, grifos nossos).

A Polícia Civil de Varginha (MG) investiga a autoria de um vídeo com imagens pornográficas que circulou em uma 
escola da cidade. Nas gravaçóes, que estão em dois aparelhos de celular, aparecem três rapazes e uma garota de 14 anos em cenas de sexo. (VÍDEO..., [2012], grifo nosso).

Por meio dessas enunciaçóes, evidenciamos que as escolas vêm servindo como ambiente para a produção de vídeos e fotos que escancaram a sexualidade dos sujeitos e como um espaço de repercussão sobre o sexting. Tal indício mostra-nos que as temáticas relacionadas à sexualidade estão presentes no cotidiano escolar, e imbricadas em diversas situaçôes, como nas práticas dos/as professores/as e dos/as alunos/as, no uso das tecnologias digitais, no namoro no corredor, no ato sexual que ocorre dentro dessa instituição, entre outros casos. Nesse sentido, a prática do sexting confirma a ideia de que a escola é um espaço sexualizado. De acordo com Michel Foucault (2007a, p. 54):

As instituiçóes escolares ou psiquiátricas com sua numerosa população, sua hierarquia, suas organizaçóes espaciais e seu sistema de fiscalizaçáo constituem, ao lado da família, uma outra maneira de distribuir o jogo dos poderes e prazeres; porém, também indicam regióes de alta saturação sexual com espaços ou ritos privilegiados, como a sala de aula, o dormitório, a visita ou a consulta. Nelas são solicitadas e implantadas as formas de uma sexualidade não conjugal, não heterossexual, não monogâmica.

Com isso, a escola pode ser entendida como um espaço privilegiado para emergência das questóes relacionadas à sexualidade, pois existem diversos sujeitos convivendo e relacionando-se nesse âmbito. Esta pode ser considerada uma instituição de máxima saturação sexual. O sexting quando repercute e é realizado na escola reforça a ideia de Michel Foucault, de que essa instituição é um lugar incitador e multiplicador de situações que envolvem a sexualidade. Além disso, essa prática, quando realizada no âmbito educativo, contribui para a proliferação de uma sexualidade que não se restringe a casais monogâmicos e ditos legítimos. Ou seja, é um lugar propício para a emergência de práticas sexuais consideradas subversivas.

Nesse sentido, a sexualidade, assim como sexting, não é um tema privado. Por isso, é preciso problematizar os entendimentos que trazem essas questôes apenas sob o viés de sua pertença ao âmbito privado. Essa temática deve ser debatida pela escola de forma sistemática, pois se trata de um assunto que envolve questóes políticas. Também pode ser entendido como um campo de disputa, pois existem conflitos de opinióes sobre esse tema. Para Louro (1998, p. 86), "a sexualidade, não há como se negar, é mais do que uma questão pessoal e privada, ela se constitui num campo político, discutido e disputado". 
Nos materiais analisados, é possível verificar que a escola é entendida como uma instância de destaque para realizar discussóes e problematizações em relação às temáticas vinculadas à sexualidade. Assim, essa instituição é um ambiente propício para os debates em relação à prática do sexting. Como podemos evidenciar nas enunciaçôes a seguir:

A pouca ou nenhuma orientaçáo ministrada nas escolas também é uma lacuna significativa. Desde 1998, o Ministério da Educaçáo sugere que a educaçẫo sexual seja introduzida nas instituiçōes de ensino. Por não ser uma disciplina curricular, algumas acolhem, outras não. (SEXO..., 2009).

A psicóloga Kátia Kos alerta que é preciso discutir mais o tema sexualidade na escola. (VÍDEO..., 2011a).

A Safernet tem trabalhado na formação de mais de 4 mil educadores no Brasil. São aplicadas sugestóes de exercício nas salas de aula para trabalhar esse tema. (TOMAZ, 2010).

Para a Secretaria de Estado da Educaçáo (SEED), casos como este devem ser combatidos com informaçấo. "Nós temos ainda um índice muito alto de gravidez na adolescência, de incidência de doenças sexualmente transmissíveis e tudo isso por uma experiência de sexualidade precoce. Então, a conversa é muito importante para que eles entendam quais são os riscos de atos impensados", disse Alayde Digiovanni, superintendente da Secretaria de Educaçáo. (ANGELI, 2009).

Alguns estudos, como os realizados por Paula Ribeiro (2002), Suzana Barros (2010) e Izaura Cruz (2008), vêm mostrando que as escolas discutem sobre as questóes relacionadas à sexualidade. No entanto, as abordagens ainda estáo atreladas a um discurso biológico, em que temas como a fisiologia e a morfologia dos sistemas genitais, a reprodução, o uso de métodos contraceptivos, a higiene e as doenças sexualmente transmissíveis acabam sendo enfocados. Tais discussóes são realizadas principalmente nas disciplinas de Ciências e Biologia. Assim, o debate sobre tais abordagens se torna legítimo na escola. De acordo com Cruz (2008, p. 5):

[...] é recorrente a necessidade de vinculação da discussão de sexualidade a conteúdos "científicos", havendo referências freqüentes a: "apresentar para os/as estudantes uma linguagem mais adequada"; "utilizar termos científicos"; e a propria vinculaçáo das discussões de sexualidade aos conteudos relativos aos aparelhos reprodutores. Tal posição nos parece uma tentativa desses/as professores/as de legitimar a discussão de sexualidade a partir do argumento científico. 
Nesse sentido, parece que a discussão relacionada à sexualidade nas escolas se restringe ao discurso científico, posicionando esse tema como de natureza biológica, que é universal e vivenciado por todos/as de forma homogênea, independentemente de questóes sociais, culturais e históricas. A sexualidade acaba sendo discutida de forma pontual e esporádica, tornando-se um assunto a ser abordado apenas nas aulas de Ciências e Biologia, principalmente quando o/a professor/a está trabalhando os conteúdos relacionados ao sistema genital.

Tal enfoque impossibilita que as discussôes sobre a prática do sexting ocorram no âmbito da escola. Entendemos que as discussóes vinculadas à sexualidade devem ser conduzidas de forma sistemática, ou seja, ao longo de diversos momentos do ano letivo. Defendemos que, além de abordar as questóes biológicas, sejam também discutidos aspectos culturais, históricos e sociais, e que sejam incorporadas discussóes sobre a diversidade sexual e de gênero, violência sexista e homofóbica e as diversas formas de viver os prazeres e desejos entre outras abordagens. Assim, estaríamos contribuindo para que fenômenos como o sexting, que envolvem as questôes relacionadas aos corpos, aos gêneros, às sexualidades e às tecnologias digitais, sejam debatidas na escola.

Entendemos ser importante que a sexualidade seja incorporada nas práticas pedagógicas escolares, abordando temas como a prática do sexting, a distinção entre o público e privado etc. Tais discussóes devem problematizar os efeitos de tais práticas na vida dos jovens, pois publicizar a vida íntima (sexualidade) pode trazer algumas consequências para os/as protagonistas do sexting, tais como: ser alvo de deboches, ser agredido/a, ser ridicularizado/a. É importante salientar que alguns/algumas protagonistas dessa prática foram alvo de bullying, de forma bastante severa. Existem casos em que os/as adolescentes tiveram que trocar de escolas, bairros, cidades e, inclusive, há casos de suicídios.

Outra forma de envolvimento da escola com o sexting é realizado quando a mídia expóe essa instituição em suas matérias e reportagens. Como podemos perceber nos segmentos abaixo:

A Polícia Civil de São Carlos, já sabe quem divulgou na internet um vídeo onde um casal de adolescentes aparecia fazendo sexo oral em uma sala de aula da Escola Estadual Jesuíno de Arruda. (POLÍCIA..., 2011, grifo nosso).

O vídeo com as imagens pornográficas teria sido feito no interior da Escola Estadual Batista Leite, que fica localizada na rua Coronel José Vicente, no Centro. (VÍDEO..., 2010. grifo nosso). 
Um vídeo de sexo entre alunos dentro do banheiro do Colégio Estadual do Paraná (CEP), a maior escola pública do Paraná, foi parar na internet. (VÍDEO..., [2009], grifo nosso).

A Polícia Judiciária Civil prendeu na manhã desta sexta-feira (14), um jovem de 18 anos, acusado de ter divulgado imagens de uma adolescente nua, aluna do Colégio Maxi, em Cuiabá. (POLÍCIA..., 2012, grifo nosso).

Ao analisarmos esses excertos, constatamos que a escola acaba sendo exposta pela mídia, pois o nome e imagens da instituição são disseminados e expostos para todos/as, quando postados na internet. Entendemos que ao identificá-la, a mídia, de certa forma, acaba tornando-a alvo de apontamentos e culpabilizações. Essa instituição se torna alvo de tamanha exposição, pois, ao longo da história, foi se constituindo como uma instância disciplinar, que deveria vigiar e controlar os corpos e as sexualidades das crianças e dos/as adolescentes, para que comportamentos considerados subversivos, como o sexting, por exemplo, não ocorressem em seu interior. Segundo Foucault (2007a), a partir do século XVIII, diversas instituiçôes, inclusive a escola, foram se constituindo como espaços de controle. Desse momento em diante, "o sexo das crianças e dos adolescentes passou a ser um importante foco em torno do qual se dispuseram inúmeros dispositivos institucionais e estratégias discursivas" (FOUCAULT, 2007a, p. 36). Assim, a fim de realizar o disciplinamento dos corpos e das sexualidades, as escolas produziram algumas estratégias normalizadoras, que tinham como objetivo regular os comportamentos, pensamentos, atitudes, desejos e prazeres dos sujeitos. Quando a escola "falha" nessa tarefa, acaba sendo responsabilizada pelos atos dos sujeitos que desta fazem parte. A mídia, ao expor imagens e fotos da instituição, onde os casos do sexting ocorrem, acaba por penalizar e expor essa instância.

Alguns vídeos caseiros de relaçóes sexuais foram produzidos com os/as protagonistas uniformizados. Esse fato tornou-se algo a ser mencionado nos materiais publicados na internet. Assim, a mídia acaba envolvendo de alguma forma a escola nos casos relacionados ao sexting.

No vídeo é possível ver a garota ajoelhada com uniforme da escola e o estudante sentado em uma cadeira. Tudo aconteceu dentro da sala de aula. (VÍDEO..., 2011b, grifo nosso).

Um menino de 15 e uma menina de 14 anos gravaram cenas de sexo, uniformizados, dentro da sala de aula de uma escola pública na cidade de São Carlos, interior de São Paulo com um celular. (ADOLESCENTES..., 2011, grifo nosso).

As filmagens mostram quatro pessoas: dois rapazes e duas adolescentes, sendo que três deles estudam na Escola Estadual 
Mizael Pinto Neto, no centro da cidade. No vídeo, as meninas aparecem uniformizadas. (VÍDEO..., 2009a, grifo nosso).

Ao olhar os fragmentos, evidenciamos que a mídia procura salientar de alguma forma o uso do uniforme pelos/as protagonistas da prática do sexting. Entendemos que essa ênfase no uniforme está ligada à questão de pertencimento à escola. Louro (2007) salienta que, em sua época escolar, o uso de uniforme estava vinculado à imagem da escolar e à constituição desse espaço.

Talvez se esperasse que nós fôssemos, também, uma espécie de estudante "padrão". Lembro-me de ouvir, sempre, a mensagem de que, vestidas com o uniforme da escola, nós "éramos a escola"! Isso implicava a obrigação de manter um comportamento "adequado", respeitoso e apropriado, em qualquer lugar, a qualquer momento. (LOURO, 2007, p. 19).

Nesse sentido, o uniforme é um demarcador identitário das escolas, podendo ser considerado um gênero simbólico, que, ao ser corporificado em uma determinada instância social, carrega consigo tudo o que uma determinada instituição acredita e defende. Assim, quando os/as estudantes utilizam essa vestimenta estão expondo os ideais, valores, filosofia e pressupostos. Dessa forma, espera-se que os/as alunos/as tenham comportamentos considerados "adequados" por uma determinada instituição. Estar uniformizado é, de alguma forma, representar a instituição. O uso de tal vestimenta "[...] exige do aluno uma postura exemplar, zelando assim pela imagem da instituição onde estudam e inevitavelmente também representam, sem importar se estâo dentro ou fora da escola" (MARCON, 2010, p.17-18).

Quando os/as estudantes transgridem as regras, como exibir a sexualidade para uma multidão, por exemplo, não só eles/elas são culpabilizados, mas a escola também fica marcada e reconhecida pela subversão ocorrida, tornando-se alvo de denúncias e apontamentos por parte da mídia.

Ao analisarmos esses materiais, verificamos que vários sujeitos são convocados a falar sobre essa prática, tais como delegado de polícia, psicólogo/a, conselheiro/a tutelar, diretor/a da escola. A seguir, apresentamos apenas enunciaçôes que remetem aos diretores/as das escolas onde a prática ocorreu ou teve repercussão:

A diretoria de ensino do município vai apurar o fato para saber se houve falha por parte da escola. O Conselho Tutelar encaminhou o caso para a promotoria da Vara da Infância e Juventude. (ALUNA..., 2011, grifo nosso).

O conselho já ouviu inclusive a direçáo da escola e os pais dos adolescentes, tendo encaminhado as denúncias para a polícia e a promotorias da infância. (VÍDEO..., 2010, grifo nosso). 
Os/as diretores/as escolares possuem várias atribuiçóes na escola. Eles/as estáo envolvidos com: a gestâo escolar, os planejamentos, a construção dos currículos, o desenvolvimento profissional, entre outras questôes. Segundo Libâneo, Oliveira e Toschi (2007, p. 355):

[...] as áreas de atuaçõos desses profissionais estão divididas em três blocos: o primeiro, de áreas vinculadas às finalidades da escola (projeto, currículo, ensino); o segundo, daquelas relacionadas aos meios (praticas de gestão e desenvolvimento profissional); o último, o da avaliação, envolvendo todas as demais áreas, incluindo os objetivos e os resultados.

Como esses/as profissionais são considerado os/as responsáveis pela administração da instituição escolar, são eles/as que respondem pela escola, principalmente quando acontece algo que é entendido como subversivo nesse ambiente.

Assim, compreendemos que são os/as diretores/as os sujeitos convocados a discutir sobre os casos que envolvem a prática do sexting, pois esse fenômeno é entendido como algo que subverte a ordem e, por isso, trata-se de um problema a ser solucionado pelas escolas. Quando os/as diretores/as são convocados/as a falar sobre as situaçôes envolvendo o fenômeno do sexting, estes/as devem informar sobre: a repercussáo do caso na escola, as providências que a escola tomou nessa situaçáo, o que foi feitos com os/as alunos/as praticantes do sexting. Além disso, são chamados a dar explicaçóes sobre como eles/as permitiram que as fotos e vídeos fossem produzidos interior da instituição. Assim, a escola acaba sendo culpabilizada por possibilitar que os materiais tenham sido produzidos em suas dependências.

Os/as diretores/as são considerados os sujeitos que devem estar envolvidos na resolução de problemas escolares; ou seja, são eles/as os/as qualificados/as a discutir sobre os casos que envolvem o sexting. Para Foucault (2007b, p. 37), "[...] ninguém entrará na ordem do discurso se não satisfazer a certas exigências ou se não for, de início, qualificado para fazê-lo". Tais enunciaçóes possibilitam-nos evidenciar o discurso do saber autorizado: existem pessoas e campos do saber que têm o direito privilegiado de falar sobre determinados temas.

\section{Enfim...}

Estudar o fenômeno do sexting tem nos possibilitado perceber as reconfiguraçóes pela qual a sexualidade está passando, dentre estas a sua transformação em algo a ser visibilizados por meio das tecnologias digitais. Assim, emergem outras 
formas de vivenciar os prazeres e desejos, pois entendemos que essas modificaçóes estão atreladas a algumas questóes sociais, históricas, econômicas, políticas e culturais. Para Louro (2007, p. 9), as "várias possibilidades de viver prazeres e desejos corporais sáo sempre sugeridas, anunciadas, promovidas socialmente (e hoje possivelmente de forma mais explicita do que antes)".

Verificamos que a escola acaba envolvida nas questôes relacionadas ao sexting, quando serve de cenário para a produção dos vídeos e fotos e quando se torna o espaço de discussão, comentários e repercussão dessa prática. Isso mostra-nos o quanto essas questôes estão presentes no cotidiano dessa instituição.

Nos materiais analisados, é mencionada a importância das temáticas vinculadas à sexualidade a ao sexting de serem discutidas nas escolas. Entendemos que a escola é um espaço sexualizado, que precisa implementar discussôes sobre os temas relacionados à sexualidade em suas práticas pedagógicas. No entanto, acreditamos que as discussóes escolares devam ir além do discurso biológico, possibilitando que os/as estudantes possam pensar e repensar em seus modos de viver a sexualidade.

Ao analisarmos o material empírico, notamos que a mídia expóe a escola quando cita o nome e as fotos das instituições envolvidas como casos do sexting. Desse modo, a mídia acaba "punindo" essa instituição, que acaba sendo responsabilizada pela ocorrência de tais casos. Consideramos que esse destaque que a mídia dá à escola está vinculado ao entendimento de que estas são instâncias disciplinadoras, que devem estar envolvidas no controle e normatização dos sujeitos.

Outro modo de envolver a escola com esses casos é quando o material analisado salienta que os/as protagonistas dos vídeos e fotos que foram produzidos estavam vestidos com o uniforme escolar. Tal enfoque está relacionado à questão identitária, pois estar com essa vestimenta é representar uma determinada instituição. Quando os/as envolvidos/as em casos de sexting mostram o uniforme é como se estivessem exibindo um padrão que é seguido nesse espaço. Para Dinah Beck (2012, p. 214), o uniforme acaba constituindo uma "[...] identidade coletiva dos/as estudantes com sua instituição de ensino".

Cabe salientar que a mídia sempre procura a escola, para saber o seu posicionamento sobre a prática do sexting, realizada por seus alunos/as. Nos materiais analisado, são os/as diretores/as que "falam" sobre o assunto. Assim, esses/as profissionais são considerados/as os/as sujeitos/as autorizados/as a falar sobre o posicionamento da instituição sobre esses casos.

Nesse viés, entendemos que este trabalho contribui para pensarmos a importância de discutirmos sobre a sexualidade e sobre as tecnologias digitais e suas implicaçôes na escola, que acaba sendo envolvida de alguma forma nos casos de sexting. 
Entendemos que fenômenos como esse devam ser problematizados, a fim de que os/as estudantes possam (re)pensar sobre a sexualidade em sua vida cotidiana.

\section{Notas}

\footnotetext{
${ }^{1}$ Para maiores informaçôes: <www.eukidsonline.net>.

${ }^{2}$ Esse conceito pode ser entendido como uma rede heterogênea, de tudo o que é dito e não dito sobre um determinado domínio, em um determinado momento histórico em nossa sociedade, que tem como objetivo responder a uma urgência. Assim, o dispositivo emerge com a função de normalizar e controlar os corpos dos sujeitos, a fim de que eles possuam determinados comportamentos (FOUCAULT, 2008).
}

\section{REFERÊNCIAS}

ADOLESCENTES fazem vídeo pornográfico em escola do interior de São Paulo. R7 Notícias, São Paulo, 27 fev. 2011. Disponível em: <http://noticias.r7.com/saopaulo/noticias/adolescentes-fazem-video-pornografico-em-escola-do-interior-de-saopaulo-20110227.html>. Acesso em: 15 jun. 2012.

ALUNA quis ser filmada durante sexo. Youpode, 23 fez. 2011. Disponível em: $<$ http://youpode.com.br/?p=37315\%23more-3731523.02.1115H06M>. Acesso em: 16 set. 2012.

ANGELI, Gladson. Alunos são afastados após filmar cena de sexo em banheiro de colégio. Gazeta do Povo, Curitiba, 21 out. 2009. Disponível em: <http://www.gazetadopovo.com.br/vidaecidadania/conteudo.phtml?id=936316>. Acesso em: 15 jun. 2012.

BARROS, Suzana da Conceição de. Corpos, Gêneros e Sexualidades: um estudo com as equipes pedagógica e diretiva das escolas da região sul do RS. Rio Grande. 2010. Dissertação (Mestrado em Educação em Ciências) - Universidade Federal do Rio Grande, Rio Grande, RS, 2010.

BECK, Dinah Quesada. Com que roupa eu vou? Embelezamento e consumo na composição dos uniformes escolares infantis. Porto Alegre, 2012. Tese (Doutorado em Educação) -Universidade Federal do Rio Grande do Sul, Porto Alegre, 2012. BRASIL. Ministério de Comunicação Social. Secretaria dos Direitos Humanos. Estatuto da criança e do adolescente. Brasília: MEC/ACS, 2005. 
CRUZ, Izaura Santiago da. Percepçóes de professoras de ciências sobre gênero e sexualidade e suas implicaçôes no ensino de ciências e nas práticas de educação sexual. In: FAZENDO GÊNERO, 8., 2008, Florianópolis. Anais... Florianópolis, SC: UFSC, 2008. Disponível em: <http://www.fazendogenero.ufsc.br/8/sts/ST10/Izaura_Santiago_da_Cruz_10.pdf> . Acesso em: 18 mar. 2014.

FISCHER, Rosa Maria Bueno. Foucault e a Análise do discurso em educação. Cadernos de Pesquisa, São Paulo, n. 114, p. 197-223, nov. 2001.

FOUCAULT, Michel. História da sexualidade: a vontade de saber. 18. ed. Rio de Janeiro: Graal, 2007a.

FOUCAULT, Michel. A Ordem do discurso. Tradução de Laura Fraga de Almeida Sampaio. São Paulo: Loyola, 2007b.

FOUCAULT, Michel. Microfisica do poder. 25. ed. Rio de Janeiro: Graal, 2008. FOUCAULT, Michel. A arqueologia do saber. 7. ed. Rio de Janeiro: Forense Universitária, 2009.

FRAGOSO, Suely; RECUERO, Raquel; AMARAL, Adriana. Métodos de pesquisa para internet. Porto Alegre: Sulina, 2012.

HALAVAIS, Alexander. Prefácio. In: FRAGOSO, Suely; RECUERO, Raquel; AMARAL, Adriana. Métodos de pesquisa para internet. Porto Alegre: Sulina, 2012. p. $11-16$.

LIBÂNEO, José Carlos; OLIVEIRA, João Ferreira de; TOSCHI, Mirza Seabra. Educação Escolar: políticas, estrutura e organização. São Paulo: Cortez, 2007. (Coleção Docência em Formação: saberes pedagógicos).

LOURO, Guacira. Sexualidade: liçóes da escola. In: MEYER, Dagmar E. Estermann (Org.). Saúde e sexualidade na escola. Porto Alegre: Mediação, 1998. p. 86-96. (Cadernos Educação Básica).

LOURO, Guacira. Pedagogias da sexualidade. In: LOURO, Guacira. O corpo educado. 2. ed. Belo Horizonte: Autêntica, 2007. p. 7-34.

LOURO, Guacira. Gênero, sexualidade e educação: uma perspectiva pósestruturalista. 10. ed. Petrópolis, RJ: Vozes, 2008.

MARCON, Mônica D'Andréa. Aspectos históricos do uso dos uniformes escolares: reflexôes no campo da educação e da moda (1940-2000 Caxias do Sul). 2010. Dissertação (Mestrado em Educação) - Universidade de Caxias do Sul, Caxias do Sul, RS, 2010. 
RIBEIRO, Paula Regina Costa. Inscrevendo a sexualidade: discursos e práticas de professoras das séries iniciais do Ensino Fundamental. Porto Alegre, 2002. Tese (Doutorado em Ciências Biológicas: Bioquímica) - Universidade Federal do Rio Grande do Sul, Porto Alegre, 2002.

POLÍCIA já sabe quem divulgou vídeo de alunos fazendo sexo oral em sala de aula. São Carlos Dia e Noite, Sáo Carlos, SP, 18 nov. 2011. Disponível em:

<http://www.saocarlosdiaenoite.com.br/websc/20225-pol\%C3\%ADcia-j\%C3\%A1sabe-quem-divulgou-v\%C3\%ADdeo-de-alunos-fazendo-sexo-oral-em-sala-de-aula>. Acesso em: 20 jun. 2012.

POLICIA Civil prende jovem que divulgou foto de adolescente nua na internet. Olhar Direto, Cuibá, 15 jun. 2012. Disponível em:

<http://www.olhardireto.com.br/noticias/exibir.asp?noticia=Policia_Civil_prende_jo vem_que_divulgou_foto_de_adolescente_nua_na_internet\&id=262674 $>$. Acesso em: 20 jun. 2012.

SAFERNET. Infográfico:Você navega com segurança? SaferNet Brasil, [2012]. Disponível em: <http://divulgue.safernet.org.br/banners/infografico.png >. Acesso em: 30 jul. 2012.

SIBILIA, Paula. O Show do eu: a intimidade como espetáculo. Rio de Janeiro: Nova Fronteira, 2008.

SEXO cada vez mais cedo. Istoé Independente, São Paulo, n. 2056, 8 abr. 2009. Disponível em:

$<$ http://www.istoe.com.br/reportagens/10862_SEXO+CADA+VEZ+MAIS+CEDO Sexo\%2520cada\%2520vez\%2520mais\%2520cedo\%2520Reportagem\%252>. Acesso em: 15 jun. 2012.

TOMAZ, Kleber. Adolescentes aderem ao 'sexting' e postam fotos sensuais na internet. G1, São Paulo, 2 maio 2010. Disponível em: <http://g1.globo.com/saopaulo/noticia/2010/05/adolescentes-aderem-ao-sexting-e-postam-fotos-sensuais-nainternet.html>. Acesso em: 15 set. 2012.

VEIGA-NETO, Alfredo. Pensar a escola como uma instituição que pelo menos garanta a manutenção das conquistas fundamentais da Modernidade. In: COSTA, Marisa Vorraber. A escola tem futuro? Rio de Janeiro: DP\&A, 2003. p.103-126.

VÍDEO de sexo no banheiro entre adolescentes do Paraná (CEP). Dicas Grátis na Net, [2009]. Disponível em: <http://dicasgratisnanet.blogspot.com.br/2009/10/ video-de-sexo-no-banheiro-entre.html >. Acesso em: 18 jun. 2012. 
VÍDEO de sexo entre adolescentes deixa pais perplexos em Aracruz. Gazeta Online, Vitória, ES, 20 maio 2009a. Disponível em: <http://gazetaonline.globo.com/_conteudo/2009/05/90123video+de+sexo+entre+adolescentes+deixa+pais+perplexos+em+aracruz.html $>$. Acesso em: 18 jun. 2012.

VÍDEO de sexo entre alunos no ginásio da escola no Pará acaba na internet. Youpode, 23 out. 2009b. Disponível em: <http://youpode.com.br/?p=25575>. Acesso em: 18 jun. 2012.

VÍDEO de adolescentes fazendo sexo no interior de uma escola em Sousa, no Sertão paraibano. Trabalho Feitos, set. 2010. Disponível em:

$<$ http://trabalhosfeitos.blogspot.it/2010/09/video-de-adolescentes-fazendo-sexono.html>. Acesso em: 18 jun. 2012.

VÍDEO com cenas de sexo entre jovens causa polêmica em escola de Belém. Saiu no jornal, Belém, 24 fev. 2011a. Disponível em:

$<$ http://www.saiunojornal.com.br/video-com-cenas-de-sexo-entre-jovens-alunoscausa-polemica-em-escola-de-belem-menore.html>. Acesso em: 18 jun. 2012.

VÍDEO polêmico denuncia casal de adolescentes fazendo sexo oral em banheiro de escola. Blogando 2.0, mar. 2011b Disponível em:

$<$ http://www.blogando20.com/2011/03/video-polemico-denuncia-casal-deadolescentes-fazendo-sexo-oral-em-banheiro-de-escola.>. Acesso em: 18 jun. 2012.

VÍDEO com cenas de sexo entre adolescentes vai parar na polícia. Saiu no Jornal, Varginha, [2012]. Disponível em:

$<$ http://www.saiunojornal.com.br/video-com-cenas-de-sexo-entre-adolescentes-vaiparar-na-policia-alunos-escola-varginha-x.html>. Acesso em: 18 jun. 2012.

WOBETO, Simone. Cenas de sexo entre adolescentes se espalham em Bom Retiro do Sul. ClicRBS, Lajeado, RS, 16 abr. 2011. Disponível em:

$<$ http://wp.clicrbs.com.br/lajeado/2011/04/16/cenas-de-sexo-entre-adolescentes-seespalham-em-bom-retiro-do-sul/?topo=77,1,1>. Acesso em: 21 jun. 2012. 


\section{Sexting in adolescence: problematizing its effects on the school environment}

\section{Abstract}

In this article, we have the purpose of analyze the phenomenon of sexting in some materials such as magazines, newspapers, TV shows and comments posted on internet, aiming to discuss how this practice is connected to the school. The word sexting is the result of the union of two words, sex and texting. This concept describes a socio-cultural practice that consists of sharing written messages, pictures and videos, with erotic / sensual / sexual connotation, using digital technologies. This work has, thus, a qualitative characteristic and is linked to social researches. For the data production, we used the internet as a research tool. In order to analyze the collected data, we used tools from the Foucauldian analysis of speech. While analyzing the data, we verified that the school is linked to questions related to sexting, because when it is not used as a background for the production of pictures and videos, it becomes an environment for discussion, comments and repercussion of that practice. In addition, the massive media, while mentioning the name, divulging the address and publicizing pictures of the schools involved in sexting cases, ends up exposing and "punishing" these institutions. We also evidenced that the school is understood as an important environment for discussions related to the sexualities. Given these points, we understand that the sexting has been producing effects on the school, which indicates the need of this instance to discuss subjects related to bodies, sexualities, genders and technologies, going beyond the biologicist approach.

Keywords: Sexting. School. Digital Technologies.

\section{Sexting en la adolescencia: problematizando sus efectos en el espacio escolar}

\section{Resumen}

En este artículo, tenemos el propósito de analizar el fenómeno sexting en algunos materiales - reportajes, informes, programas televisivos, comentarios -, expuestos en la internet, con el objetivo de discutir cómo esa práctica está entrelazada a la escuela. El término sexting proviene de la unión de dos palabras: sex (sexo) texting (envío de mensajes). Ese concepto describe una práctica sociocultural que consiste en el compartir mensajes escritas, fotos y vídeos, de carácter erótico/sensual/sexual, por medio de las tecnologías digitales. Este trabajo es de carácter cualitativo y está vinculado a las pesquisas sociales. Para la producción de los datos, utilizamos la internet como instrumento de pesquisa. Para el análisis de los datos colectados, utilizamos algunas herramientas de análisis del discurso foucaultiano. Al realizar el estudio de los datos, verificamos que la escuela está vinculada a las cuestiones relacionadas al sexting, pues cuando esta no sirve como escenario para la producción de los videos y fotos, se convierte en un espacio de discusión, comentarios y de repercusión de esa práctica. Además, los medios, al mencionar el nombre, detallar la dirección y publicar fotos de las escuelas conectadas con los casos del sexting, acaba exponiendo y "puniendo" esa institución. También evidenciamos que la escuela es entendida como un espacio importante para las discusiones relacionadas a las sexualidades. En ese sentido, entendemos que el sexting ha producido efectos en la escuela, apuntando la necesidad de que esa institución pueda discutir temas pertinentes a las sexualidades, los cuerpos, géneros y tecnologías, para más allá del enfoque biologicista.

Palabras claves: Sexting. Escuela. Tecnologías digitales. 
Suzana da Conceiçáo de Barros

E-mail:suzinhab@yahoo.com.br

Paula Regina Costa Ribeiro

E-mail: pribeiro@furg.br

\section{Raquel Pereira Quadrado}

E-mail: raquelquadrado@hotmail.com

Enviado em: 6/8/2014

Aprovado em: 8/12/2014 